\title{
SONEGAÇÃO FISCAL: UM ESTUDO SOBRE A PRÁTICA DE SONEGAR NAS ORGANIZAÇÕES BRASILEIRAS.
}

Aline Cristina Bueno, Carina da Silva, Danieli Aparecida da Silva, Jeane de Moura Almeida, Liliane Machado Nogueira, Pedro Teófilo de Sá

Ciências Contábeis, Universidade do Oeste Paulista - UNOESTE, Presidente Prudente - SP. E-mail: Aline1196bueno@hotmail.com

\section{RESUMO}

O trabalho visa à sonegação fiscal nas organizações brasileiras, que deve ser vista pelo lado do governo que deixa de arrecadar os tributos e conseqüentemente tem sua receita diminuída e sobre os contribuintes que tem a obrigação de pagar os impostos corretamente e são sobrecarregados com uma carga tributária crescente. Diante dessa situação este estudo tem as seguintes problemáticas: Quais os motivos que levam as organizações brasileiras a praticar a sonegação Fiscal? E Quais as conseqüências da sonegação para o governo? Este estudo é realizado através de análise feita por pesquisa bibliográfica, documental e qualitativa, buscando justificar os fatores que levam a sonegar, beneficiando o governo com contribuições e informações. Conclui-se que as motivações que levam o contribuinte a sonegar são as mais variadas, existentes no sistema tributário brasileiro e às conseqüências é um crime que tem proporções prejudiciais, em vista que essa conduta prejudica a cobrança e arrecadação de recursos.

Palavras - chave: Sonegação Fiscal, Carga Tributária, Organizações Brasileiras, governo, contribuinte.

TAX EVASION: A study of the practice of withholding in organizations.

\begin{abstract}
The work is aimed at tax evasion in organizations, the work is aimed at tax evasion in Brazilian organizations, which should be seen by the government side that fails to collect taxes and consequently have a reduced income and on taxpayers who have the obligation to pay taxes properly and are burdened with a tax burden growing. Faced with this situation this study has the following issues: What are the reasons that Brazilian organization to practice tax evasion? And what are the consequences of tax evasion for the government? This study is conducted through analysis by bibliographical, documentary and qualitative research, seeking to justify the factors that lead to evade, benefiting the government with contributions and information.

We conclude that the motivations that lead the taxpayer to evade are varied existing in the Brazilian tax system and the consequences is a crime that has harmful proportions, a view that such conduct impairs the collection and fundraising.
\end{abstract}

Keywords: Tax evasion, tax burden, Brazilian organizations, government, taxpayer. 


\section{INTRODUÇÃO}

O problema da sonegação fiscal é tão antigo quanto os impostos em si. Em geral, os indivíduos não gostam de pagar impostos, fazem o que puderem para reduzi-los. Paralela a imposição dos antigos impérios em cobrar impostos, surge a figura da sonegação fiscal que está presente na sociedade até os dias de hoje, com muito mais sofisticação, em razão da modernização do Estado, mas se encontram também com muita evidência a sonegação pela falta de emissão do documento fiscal.

A existência do governo se faz necessária e surge como forma de organizar e disciplinar as relações existentes na sociedade, e em particular na economia, resultaria em uma série de problemas que o mercado, por si só, não tem condições de resolver. A carga tributária brasileira é alta, contribuindo para o surgimento e a intensificação do problema da sonegação fiscal.

Com base nesse tema surgem algumas questões: Quais os motivos que levam as organizações brasileiras a praticar a sonegação Fiscal? E Quais as consequências da sonegação para o governo?

O governo brasileiro tem tomado várias medidas para diminuir a sonegação fiscal, mas mesmo com a diminuição ela ainda existe. Este estudo busca justificar os fatores que levam a sonegar, beneficiando o governo com contribuições e informações.

O trabalho acerca da sonegação fiscal brasileira, além de se mostrar bastante atual, é um assunto de grande importância, pois afeta a eficiência da economia brasileira e consequentemente afeta todos os brasileiros, seja ao efetuar os pagamentos de impostos direta e indiretamente, seja pela perda de qualidade dos serviços nas áreas da educação, saúde, segurança. Procura-se fazer essa análise tendo em vista as variáveis que ocasionam o problema, assim como as consequências geradas pela sonegação, tratando-se de um tema de interesse de toda população, por influenciar diretamente nos rendimentos de cada brasileiro.

A pesquisa tem como objetivo geral estudar a sonegação fiscal nas organizações brasileiras e como objetivo especifico identificar as razões que levam as organizações brasileiras a praticar a sonegação fiscal e as suas conseqüências para o governo.

\section{METODOLOGIA}

Quanto ao método de abordagem do problema, adota-se a qualitativa. Aquilo que particulariza os trabalhos qualitativos é que eles possibilitam descrever as qualidades de determinados fenômenos ou objetos de estudo. Segundo Andrade (2010) a metodologia é o conjunto de métodos ou caminhos que são percorridos na busca do conhecimento. Dessa forma, a pesquisa bibliográfica foi desenvolvida com base em fontes já publicadas, como livros, monografias, estudos realizados por órgãos. Também será utilizada a fonte documental, que são documentos, disponíveis em sites federais oficiais, com o objetivo de apresentar dados atualizados e tornar a pesquisa mais robusta.

\section{RESULTADOS}

O presente estudo buscou contribuir para a estimação da sonegação tributária no Brasil. Por ser tema frequente de debates e de interesse de toda população, é um dos principais problemas que afetam diretamente a economia do país, provocando a diminuição da arrecadação para o governo, sobrecarregando os consumidores com altas cargas tributárias. Assim, o resultado do ato de sonegar é crime, conduta que prejudica a cobrança e arrecadação de recursos.

A partir de análises gráficas e bibliográficas foi possível visualizar o nível de desvio de arrecadação no Brasil decorrente da sonegação fiscal, identificando as empresas que mais praticam este ato, os impostos mais sonegados e a influência para toda a população. 


\section{DISCUSSÃO}

\section{SONEGAÇÃO FISCAL}

A sonegação é um dos principais problemas enfrentados atualmente pelas fazendas públicas, que tem o papel responsável de obter uma arrecadação eficiente e um sistema tributário equilibrado, Ferracini (1996.p.61) explica melhor o ato:

Doutrinamente, o tipo do crime é aquele denominado omissivo próprio. 0 não pagamento do tributo devido a fazenda pública no prazo legal consuma o delito. Por sua vez, seu núcleo é deixar de recolher o tributo no modo, tempo e lugar devidos. É o recolhimento fora do prazo ou não recolhido do tributo recebido.

A sonegação é apta a gerar grandes problemas ao mercado, o contribuinte por vontade, realiza condutas que visam a suprimir ou reduzir tributos, optando em não pagar ou pagar menos tributos, por meio da prática de condutas ilícitas.

De acordo com o Art. $1^{\circ}$ Constitui crime contra a ordem tributária suprimir ou reduzir tributo, ou contribuição social e qualquer acessório, mediante as seguintes condutas (Lei no 9.964, de 10.4.2000):

I - omitir informação, ou prestar declaração falsa às autoridades fazendárias;

II - fraudar a fiscalização tributária, inserindo elementos inexatos, ou omitindo operação de qualquer natureza, em documento ou livro exigido pela lei fiscal;

III - falsificar ou alterar nota fiscal fatura duplicata, nota de venda, ou qualquer outro documento relativo à operação tributável;

IV - elaborar, distribuir, fornecer, emitir ou utilizar documento que saiba ou deva saber falso ou inexato;

$\mathrm{V}$ - negar ou deixar de fornecer, quando obrigatório, nota fiscal ou documento equivalente, relativa à venda de mercadoria ou prestação de serviço, efetivamente realizada, ou fornecê-la em desacordo com a legislação.

Desta forma, fica caracterizado, explicitamente, que, o referido delito é um crime. Portanto, em razão da natureza do crime de sonegação fiscal é primordial a ocorrência do lançamento definitivo do tributo para que concretize a condição objetiva de punibilidade ao contribuinte.

\section{Fatores que Motivam a Sonegação Fiscal}

A sonegação fiscal tem como determinante fundamental a vontade do contribuinte. É o contribuinte que decide se ele vai honrar suas obrigações ou se vai sonegar. Segundo Siqueira e Ramos (apud LEITE, 2011, p.55) há um modelo básico de sonegar.

A sonegação é vista como um problema de alocação de portfólio: o contribuinte deve decidir qual a parcela de sua renda. Se não quiser correr nenhum risco, declara completamente sua renda; caso contrário, declara somente uma fração dela e aceita correr o risco de ser flagrado e multado.

Esse é um problema que afeta todos os contribuintes e os que dependem da máquina estatal, pois o contribuinte que paga, acaba sobrecarregado por uma alta carga tributária.

De acordo com Pinto (apud LEITE, 2011) existem dois motivos que levam a sonegação fiscal. O primeiro está relacionado ás oportunidades e recompensas em sonegar os tributos. Já o 
segundo motivo está ligado ás razões pessoais, que podemos entender como desonestidade, predisposição para o jogo e atitudes relacionadas ao sistema tributário e ao governo. Com a investigação foi possível destacar as principais percepções que influenciam a decisão do contribuinte cumprir ou não suas obrigações fiscais. São elas:

- A percepção de que a carga tributária é justa ou excessiva, em referência aos benefícios gerados à sociedade;

- A percepção de que o governo aplica adequadamente a arrecadação ou não oferece contrapartida à altura dos recursos escolhidos.

- O sentimento do contribuinte de que o governo é capaz ou não de fiscalizar com eficiência os casos de fraude fiscal;

- A facilidade ou dificuldade de entender o sistema tributário e lidar com suas complexidades e formalidades, decorrente de burocracia de serviços e processos fiscais, falta de clareza da legislação e excessivas alterações das normas;

- A percepção de equidade ou inequidade em relação ao tratamento dado pelo sistema fiscal aos contribuintes em condições idênticas.

Se o contribuinte estiver insatisfeito para cada um dos pontos levantados a predisposição do contribuinte sonegar será maior. O cumprimento das obrigações tributárias está relacionado á declaração integral e verdadeira da base tributária, ao correto cálculo da base de incidência e ao recolhimento devido.

A questão da sonegação deve ser vista pelo lado do governo que deixa de arrecadar os tributos e consequentemente tem sua receita diminuída, e depois sobre os contribuintes que tem a obrigação de pagar os impostos corretamente.

\section{Sonegação Fiscal nas Empresas Brasileiras}

O IBPT - Instituto Brasileiro de Planejamento e Tributação (2009) realizou um estudo sobre a sonegação fiscal nas empresas brasileiras. O Instituto considerou os balanços de fiscalização da Receita Federal, das Secretarias da Fazenda do Estado e Secretarias de Finanças das Capitais.

Ainda segundo IBPT foram analisadas no total 9.925 empresas de todos os setores, destas 1.417 foram empresas de pequeno porte, 5.783 de médio porte e 2.725 empresas de pequeno porte.

Tabela 1. Faturamento não declarado das empresas pesquisas em 2008.

\begin{tabular}{|l|lc|c|c|}
\hline $\begin{array}{l}\text { Porte } \\
\text { Empresas }\end{array}$ & $\begin{array}{l}\text { Faturamento não } \\
\text { declarado } \\
\text { empresas } \\
\text { pesquisadas } \\
\text { bilhões }\end{array}$ & R\$ & $\begin{array}{l}\text { Faturamento total das } \\
\text { empresas brasileiras } \\
\text { R\$ bilhões }\end{array}$ & $\begin{array}{l}\text { \% Faturamento não } \\
\text { declarado em relação } \\
\text { ao faturamento total } \\
\text { das empresas } \\
\text { brasileiras }\end{array}$ \\
\hline Pequeno Porte & 253,49 & 322,27 & $78,66 \%$ \\
\hline Médio porte & 346,53 & 476,73 & $72,69 \%$ \\
\hline Grande porte & 722,49 & $4.480,22$ & $16,13 \%$ \\
\hline TOTAL & $\mathbf{1 . 3 2 2 , 5 1}$ & $\mathbf{5 . 2 7 9 , 2 2}$ & $\mathbf{2 5 , 0 5 \%}$ \\
\hline
\end{tabular}

Fonte: IBPT (2009)

Com a tabela é possível determinar o índice de empresas que praticam a sonegação fiscal, segundo IBPT (2009) aproximadamente $25 \%$ das empresas brasileiras praticam algum tipo de sonegação.

Também foi possível apurar a sonegação pelas empresas em relação aos tributos abaixo: 
- O INSS é o tributo mais sonegado, apresentando índice de $27,75 \%$ (índice 2002: 21,02\% e índice 2005: 29,47\%);

- Em seguida está o ICMS, com índice de 27,14\% (índice 2002: 26,54\% e Índice de 2005: 26,95\%);

- O Imposto de Renda é sonegado em 26,64\% (26,77\% índice de 2002 e $27,02 \%$ índice de 2005) das empresas contribuintes;

- ISS em 25,02\% (índice 2002: 23,62\% e índice 2005: 25,66\%);

- Contribuição Social sobre o Lucro em 24,89\% (índice 2002: 24,31\% e Índice de 2005: 24,81\%);

- Imposto de Importação em 24,83\% (índice 2002: 19,08\% e índice 2005: $23,65 \%)$;

- PIS e COFINS em 22,13\% (índice 2002: 25,11\% e índice de 2005: $23,43 \%)$;

- IPI em 19,08\% (índice 2002: 21,99\% e índice 2005: 18,85\%);

- IOF em 16,55\% (índice 2002: 14,84\% e índice 2005: 15,72\%); e

- CPMF em 4,03\% (índice 2002: 7,06\% e índice 2005: 10,86\%) das empresas pesquisadas.

De acordo com os dados, o mais sonegado é a contribuição previdência devida ao INSS, que pode ser sonegado quando o empresário não registra o funcionário, não havendo registro não há geração da obrigação, mas também pode acontecer da empresa descontar o tributo do funcionário e não efetuar o pagamento devido. Segundo Leite (2011) a sonegação fiscal é demasiadamente complexa para ser mensurada, todavia sabe-se que os números são muitos altos. Isto se deve pelo o fato da alta carga tributária que afeta o governo que deixa de arrecadar os tributos, as organizações brasileiras e toda a população no pagamento de altos impostos.

\section{Consequências da Sonegação Fiscal}

Para o representante dos Auditores Fiscais, Mauro Roberto da Silva, a ação dos servidores voltada a coibir a sonegação fiscal é essencial para garantir que não haja queda na arrecadação, e os compromissos do Estado com a população sejam cumpridos. $O$ ato de sonegar, além de crime, gera perdas incalculáveis para a população, pois o dinheiro que deveria ser devidamente destinado ao Estado, fica no bolso do sonegador. É um dinheiro que poderia ser investido em áreas essenciais como saúde, educação e segurança. A população é quem mais perde com a sonegação. Pelas palavras de Lemos (1999, p.213).

Quanto às consequências da sonegação fiscal, necessário é salientar que este crime tem proporções prejudiciais incalculáveis comparados com outros previstos no Código Penal, como, a apropriação indébita e o estelionato. Isto se deve ao fato de que nestas práticas delitivas o prejuízo é sempre apurado em desfavor da Fazenda Pública, diminuindo a capacidade do Estado em prover as mínimas condições das pessoas que integram a coletividade com saúde, educação e saneamento básico, ocasionando, por outro lado, e devido a seu efeito perverso, doenças, analfabetismo, pobreza, desemprego, oneração daqueles que já contribuem.

Contudo, a sonegação começou a ser trabalhada não somente como um problema que afeta apenas aos órgãos públicos, mas como uma questão que atinge a própria sociedade, com a diminuição da arrecadação, os consumidores sofrem com altos impostos e falta de benefícios gerados pelo governo, causando impacto negativo sobre o crescimento econômico do país. 
De acordo com o Art. $1^{\circ}$ Constitui crime contra a ordem tributária suprimir ou reduzir tributo, ou contribuição social e qualquer acessório, mediante as seguintes condutas (Lei no 9.964, de 10.4.2000

Pena - reclusão de 2 (dois) a 5 (cinco) anos, e multa.

Parágrafo único. A falta de atendimento da exigência da autoridade, no prazo de 10 (dez) dias, que poderá ser convertido em horas em razão da maior ou menor complexidade da matéria ou da dificuldade quanto ao atendimento da exigência, caracteriza a infração prevista no inciso $\mathrm{V}$.

O governo brasileiro tem tomado várias medidas para diminuir a sonegação fiscal, o contribuinte desta ação pagará pelos os seus atos e se responsabilizará em suas conseqüências.

\section{CONCLUSÃO}

Através da análise realizada neste trabalho foi possível verificar que há um alto índice de sonegação, principalmente quando se trata das empresas brasileiras, com problemas de grande complexidade e de difícil mensuração. Conclui-se que as motivações que levam o contribuinte a sonegar são as mais variadas, pode-se relacioná-las a todos os problemas existentes no sistema tributário brasileiro, como a pesada carga tributária, altos gastos e aplicações inadequadas dos recursos arrecadados. Os aumentos nos gastos levam à necessidade de elevar as arrecadações, o que explica a alta carga tributária brasileira.

A insatisfação com o sistema tributário e governo, assim como a percepção da carga tributária excessiva e falta de contrapartida são os principais fatores que motivam a sonegação. Porém, só sonega quem tem chances para sonegar, é o contribuinte que decide se ele vai honrar suas obrigações ou se vai sonegar. Há problemas na estrutura tributária brasileira, gerando cargas tributárias altíssimas, sem a devida contrapartida dos serviços públicos oferecidos. Levando em consideração também as práticas de maior oportunidade por parte das empresas brasileiras em praticar sonegação fiscal.

Quanto às conseqüências da sonegação fiscal, é um crime que tem proporções prejudiciais, isto se deve ao fato de que nestas práticas o prejuízo é sempre apurado em desfavor da Fazenda Pública, é um delito que prejudica tanto ao poder público, e o contribuinte como o próprio sonegador, tendo em vista que essa conduta prejudica a cobrança e arrecadação de recursos.

\section{REFERÊNCIAS}

FERRACINI, Luiz Alberto. Do crime de sonegação fiscal. Editora de Direito, 1996. p.61.

FOLHA. Auditores Fiscais intensificaram a fiscalização no posto de Vilhena, Folha de Vilhena, 19 de março de 2015. Disponível em:

http://folhadevilhena.com.br/rdn/auditores-fiscais-intensificaram-a-fiscalizacao-no-posto-devilhena/. Acesso em :17 nov. 2015.

IBPT - Instituto Brasileiro de Planejamento Tributário. Estudos do IBPT: Estudo sobre sonegação fiscal das empresas brasileiras. Curitiba, 05 mar. 2009. Disponível em: http://www.ibpt.com.br/img/uploads/novelty/estudo/49/EstudoVeQuedaNaSonegacaoFiscalDasE mpresasBrasileiras.pdf. Acesso em:13 nov. 2015.

LEITE, Luana Priscilla Carreiro Varão. 0 sistema tributário brasileiro: análise da sonegação fiscal nas empresas brasileiras. Universidade Federal de Santa Catarina - UFSC, 2011. p.55. Disponível em: <http://tcc.bu.ufsc.br/Economia302879.pdf>. Acesso em: 13 nov. 2015. 
LEMOS, Rubin. Legalidade, crime de sonegação fiscal e o Ministério público. Revista da Fesmpdft, 1999. 213 p. Disponível em: <http://www.escolamp.org.br/arquivos/14_13.pdf>. Acesso em: 14 nov. 2015.

PINTO, Francisco Roberto. Evasão fiscal e estratégia empresarial: a percepção dos empresários brasileiros. Faculdade de Economia, Universidade de Coimbra, Coimbra, 2008. Disponível em: <http://www.robertopinto.com/pdf/coimbra.pdf>. Acesso em: 13 abr. 2011.

Presidência da República Federativa do Brasil. Legislação - Lei 4.729, de 14 de julho de 1965. Disponível em: http://www.planalto.gov.br/ccivil_03/Leis/L8137.htm. Acesso em 13 nov.2015.

RIOS, Rodrigo Sánchez. Crime Fiscal: Reflexões sobre o crime fiscal no direito tributário e no direito estrangeiro. Sergio Fabris, 1998. P. 33.

SIQUEIRA, Marcelo Lettieri; RAMOS, Francisco S. A Economia da Sonegação: teorias e evidências empíricas. Revista de Economia Contemporânea, Set./Dec. 2005. Disponível em: <http://www.scielo.br/scielo. php?pid=S141598482005000300004\&script=sci_arttext>. Acesso em: 15 maios 2011.

ANDRADE, Maria Margarida de Introdução á metodologia do trabalho científico. 10 ed. Editora Atlas S.a, 2010. p. 117. 